\title{
Similar hematological and biochemical parameters among periodontitis and control group subjects
}

\author{
Shobha Prakash ${ }^{1}$ \\ Kunaal Dhingra ${ }^{2}$ \\ Shanmuga Priya
}

\section{ABSTRACT}

Objective: There are conflicting reports in the past literature documenting the tendency of anemia in patients with periodontitis. Hence, this study was undertaken to assess whether periodontitis may cause an anemic state, by evaluating and comparing the red blood cell count, levels of hemoglobin, hematocrit, erythrocyte sedimentation rate (ESR), serum iron and serum ferritin between subjects with and without periodontitis.

Methods: In this cross-sectional study, 140 systemically healthy subjects of both sexes (mean age 46 years) were recruited as control group (50 subjects without periodontitis) and study groups comprising 30 patients each with mild, moderate and severe chronic generalized periodontitis. Periodontal parameters and orthopantamographs were taken for all the groups and then $5 \mathrm{~mL}$ venous blood samples were sent for complete blood count and biochemical analysis. Inter-group and intra-group comparisons were performed for all the assessed parameters.

Results: The periodontal parameters were significantly higher $(P \leqslant .05)$ in periodontitis patients. Except for the ESR, which was significantly higher $(P=.03)$ in the mild periodontitis group than the control group, hematological and biochemical parameters were not significantly different $(P>05)$ among the study groups or between the control and study groups. This difference was not evident even among the male and female subjects of both control and study groups $(P>05)$.

Conclusions: Within the limits of this cross-sectional study, it can be concluded that the presence and severity of periodontitis may not affect the hematological and biochemical parameters of an individual. Further long term studies are however encouraged to validate these findings. (Eur J Dent 2012;6:287-294)

Key words: Anemia; blood sedimentation; erythrocyte indices; periodontitis

1 Department of Periodontics, College of Dental Sciences, Davangere, Karnataka, INDIA

2 Department of Periodontics, N.S.V.K Sri Venkateshwara Dental College, Bangalore, Karnataka, INDIA

- Corresponding author: Dr. Kunaal Dhingra Department of Periodontics, N.S.V.K Sri Venkateshwara Dental College, Bangalore, Karnataka, INDIA Tel: +918027803522

Fax: +918027828842

Email: kunaaldhingradyahoo.co.in

\section{INTRODUCTION}

Periodontal disease is an infectious condition and an inflammatory disorder ${ }^{1}$ which can increase the risk of systemic problems like cardiovascular diseases, ${ }^{2}$ cerebrovascular diseases, ${ }^{2}$ atherosclerosis, ${ }^{3}$ preterm low birth weight, ${ }^{4}$ and diabetes mellitus. ${ }^{5}$ These reported associations indicate that periodontal diseases have systemic effects. ${ }^{1}$

Anemia is a state of reduced hemoglobin $(\mathrm{Hb})$ concentration, reduced number of circulating 
erythrocytes in the blood, or both. ${ }^{1}$ Globally, anemia affects 1.62 billion people, which is approximately $24 \%$ of the world's population.6 Majority of the anemia are characterized by low mean corpuscular volume (MCV) and are thus, classified as microcytic. ${ }^{7}$ Iron deficiency, chronic disease and thalassemia traits are the 3 leading causes of microcytic anemia. ${ }^{7}$ In the past literature, various studies have reported conflicting data for the relationship between periodontitis and anemia. In the previous studies, ${ }^{8-10}$ a tendency towards anemia was reported in periodontitis patients, but except for one study, ${ }^{8}$ other studies ${ }^{9,10}$ have suggested that anemia was one of the causes of destructive periodontitis and not a consequence. Likewise, a study by Wakai et al ${ }^{11}$ did not observe a relationship between increased Community Periodontal Index of Treatment Needs (CPITN) scores and $\mathrm{Hb}$ levels.

On the other hand, 2 recent studies ${ }^{12,13}$ have reported lower red blood cell (RBC) counts, lower hematocrit (Hct) levels, lower $\mathrm{Hb}$ levels and higher ESR values in periodontitis patients. The possible etiology cited for decreased blood counts was the downregulation of erythropoiesis in the bone marrow by proinflammatory cytokines due to periodontal disease. ${ }^{12,13}$ This condition is termed as anemia of chronic disease (ACD) and is defined as the anemia occurring in chronic infections, inflammatory conditions or neoplastic disorders that is not caused by marrow deficiencies or other diseases, and occurring despite the presence of adequate iron stores and vitamins. ${ }^{14}$ It is a type of microcytic anemia. ${ }^{7}$

It is apparent from the literature that the problem of anemia in relation to periodontal disease still has lacunae for intensive research. Hence, the present study was undertaken to assess whether periodontitis may cause anemic states, by evaluating and comparing the RBC counts, levels of hemoglobin, Hct, serum iron and serum ferritin between patients with and without chronic periodontitis.

\section{MATERIALS AND METHODS}

Patient selection and clinical assessment

One hundred and forty subjects of both sexes lage group 35-65 years; mean age 46 years) were selected for this cross-sectional study from the population in and around Davangere district, Kar- nataka, India, who visited or were referred to the outpatient clinic of the Department of Periodontics, College of Dental Sciences, Davangere for diagnosis and treatment of periodontal disease. The inclusion criteria was as follows: patients with and without periodontitis as evident clinically and radiographically; good general health without any systemic diseases or acute or chronic medical conditions including diabetes, viral, fungal or bacterial infections; and no history of periodontal therapy prior to 6 months of examination, use of vitamin or iron supplementation within the previous 3 months, any special dietary requirements (e.g. coeliac disease), or current usage of antibiotics or steroids. The exclusion criteria included pregnant and lactating mothers, smokers, patients with recent trauma or tooth extractions, and patients with the lack of desire to participate in the study. None of the patients were alcohol consumers. All the procedures were fully explained to the patients before the study, and written informed consent was obtained from all the patients. The study protocol and consent form were approved by the Ethical Committee, Rajiv Gandhi University of Health Sciences, Karnataka, India, and the study was conducted on the basis of the principles outlined in the Declaration of Helsinki of 1975, as revised in 2008, on experimentation involving human subjects. The study was carried out between August 2010 and November 2010.

The subjects (Table 1) were divided into the control group and study group. The control group included 50 subjects ( 27 men and 23 women) with periodontal sites that had a probing depth $\leqslant 3 \mathrm{~mm}$, no clinical attachment loss and no bone loss radiographically. The study group included 90 chronic generalized periodontitis patients $(51$ men and 39 women) with periodontal sites that had a probing depth $\geqslant 4 \mathrm{~mm}$, clinical attachment loss $\geqslant 2 \mathrm{~mm}$ with bone loss radiographically. The study group comprised of 30 patients each with mild $12 \mathrm{~mm}$ clinical attachment loss), moderate (3 - $4 \mathrm{~mm}$ clinical attachment loss) and severe ( $\geqslant 5 \mathrm{~mm}$ clinical attachment loss) periodontitis. Thus, these study group patients had a similar extent of disease but varying disease severity in accordance with the 1999 International Workshop ${ }^{15}$ characterization of chronic periodontitis (based on disease severity). The study and control group subjects were matched for age and socioeconomic status. 
Examination of the patients was preceded by a thorough medical history of all the groups. A complete periodontal examination was undertaken using a mouth mirror and a UNC-15 graduated periodontal probe (Hu-Friedy, Chicago, IL, USA) by a single examiner (SP). Periodontal status was assessed by using clinical parameters such as plaque index $(\mathrm{P} I),{ }^{16}$ gingival index $(\mathrm{G} I),{ }^{17}$ probing depth (PD) and clinical attachment level (CAL). Six sites per tooth (buccal, mesio-buccal, disto-buccal, lingual, mesio-lingual, and disto-lingual) were evaluated. PD was measured from the free gingival margin (GM) to the base of the pocket. CAL was determined by measuring the distance between the cemento-enamel junction (CEJ) and the GM, adding the PD at the same site. An orthopantamograph was taken for all the groups to assess the bone loss.

Hematological and biochemical assessment

Blood samples ( $5 \mathrm{~mL}$ ) were collected between 9.30 and $11.30 \mathrm{AM}$ by venepuncture of the cubital vein in the antecubital fossa by using a $5 \mathrm{~mL}$ disposable syringe and a 23 gauge needle. A part of the blood sample was then transferred to sterile vacuum tubes containing an anticoagulant ethylene diamine tetraacetic acid (EDTA), for whole blood analysis. The remaining blood was collected in sterile vacuum tubes with no added anticoagulant and was kept at room temperature for $2 \mathrm{~h}$, where it was allowed to clot, as this was designated for serum separation. The tubes were then transported to a laboratory (Central laboratory, Bapuji Hospital, Davangere, Karnataka, Indial for processing within $4 \mathrm{~h}$ after venepuncture and were analyzed by using hematological investigations consisting of the RBC count, Hct, estimation of $\mathrm{Hb}$, $\mathrm{MCV}$, mean corpuscular hemoglobin $(\mathrm{MCH})$, mean corpuscular hemoglobin concentration $(\mathrm{MCHC}$ ), ESR, and for biochemical investigations like serum iron and ferritin.
The hematological parameters like RBC count, $\mathrm{Hct}, \mathrm{Hb}, \mathrm{MCV}, \mathrm{MCH}$ and $\mathrm{MCHC}$ were estimated in an automated blood counting machine ISYSMEX XE-2100; Sysmex Corporation, Kobe, Japan). ESR was estimated by using the Westergren method manually. Biochemical parameters like serum iron and serum ferritin were analyzed by using an automated analyzer (COBAS INTEGRA 400 plus; Roche Diagnostics, Germany).

\section{Statistical analyses}

Results were expressed as mean \pm SD values and as number and percentage values for categorical data. Student t-test was used to compare the different variables between the control and study groups (intergroup comparison). Intragroup comparisons among the various periodontitis groups were done by using the one way ANOVA test, followed by the post-hoc Tukey's test. The Z-test was used to compare the proportions (percentages) between the control and study groups. A p-value of .05 or less was considered statistically significant.

\section{RESULTS}

Table 2 shows the comparison of clinical, hematological and biochemical parameters among the study groups (intragroup) and of the study groups with the control group (intergroup). Statistical analysis showed that the clinical parameters i.e. $\mathrm{PI}, \mathrm{GI}, \mathrm{PD}$ and $\mathrm{CAL}$ were significantly higher $(\mathrm{P}<.05)$ in the study groups than the control group, whereas intragroup comparisons between the various study groups (mild, moderate and severe periodontitis) showed that the PI and PD values were not significantly different $(P>.05)$ among them. However, in case of CAL, the level of significance increased $(P<.05)$ as the disease severity increased. $G$ l was significantly greater $(P<.01)$ in the severe periodontitis $(1.59 \pm 0.44)$ than the moderate $(1.09 \pm 0.44)$ and mild periodontitis $(0.76$ \pm 0.30 ) groups; however, no significant difference

Table 1. Demographics and characteristics for control and study groups; values are means \pm standard deviations or number of subjects.

\begin{tabular}{|c|c|c|c|c|}
\hline & Control & Mild periodontitis & Moderate periodontitis & Severe periodontitis \\
\hline & $(n=50)$ & $(n=30)$ & $(n=30)$ & $(n=30)$ \\
\hline Age (years) & $45.7 \pm 5.1$ & $46.0 \pm 4.2$ & $45.8 \pm 7.3$ & $46.2 \pm 9.1$ \\
\hline Males & 27 & 17 & 16 & 18 \\
\hline Females & 23 & 13 & 14 & 12 \\
\hline No. of teeth with CAL loss $\geqslant 2 \mathrm{~mm}$ & 0 & $16.4 \pm 2.3$ & $19.2 \pm 4.8$ & $14.8 \pm 3.2$ \\
\hline
\end{tabular}


( $P>$.05) was seen between the mild and moderate periodontitis groups.

The hematological and biochemical parameters did not show a significant difference ( $P>.05$ ) between the control and study groups and also among the study groups, except for ESR values, which were significantly higher $(P<.05)$ in the mild periodontitis group $(23.0 \pm 2.6 \mathrm{~mm} / \mathrm{h})$ than the control group (17.8 $\pm 4.5 \mathrm{~mm} / \mathrm{h}$ ), as shown in Table 2 .

Tables 3 and 4 show intergroup comparison of the hematological and biochemical parameters among the male and female subjects of the control and study groups. All the hematological and biochemical parameters were non-significant $(P>.05)$ among the male and female subjects of the control and study groups.

Table 5 shows the number (\%) of control subjects and periodontitis patients with values for RBC parameters outside the reference ranges (below or above the reference range). The difference between the number $(\%)$ of patients showing RBC parameters outside the reference ranges was non-significant $(P>.05)$ between the control and study groups. The study group in comparison

Table 2. Mean \pm standard deviation and test of significance of mean values between control and study groups.

\begin{tabular}{|c|c|c|c|c|c|c|c|c|c|c|c|c|c|c|c|}
\hline \multirow{2}{*}{$\begin{array}{l}\text { S. } \\
\text { No. }\end{array}$} & \multirow{2}{*}{ Variable } & \multicolumn{2}{|c|}{ Control group (A) } & \multicolumn{2}{|c|}{ Mild Periodontitis group (B) } & \multicolumn{2}{|c|}{$\begin{array}{l}\text { Moderate Periodontitis } \\
\text { group (C) }\end{array}$} & \multicolumn{2}{|c|}{$\begin{array}{l}\text { Severe Periodontitis } \\
\text { group (D) }\end{array}$} & \multicolumn{3}{|c|}{$\begin{array}{l}\text { Intergroup comparison } \\
\text { (p - value) }\end{array}$} & \multicolumn{3}{|c|}{$\begin{array}{l}\text { Intragroup comparison } \\
\text { (p - value) }\end{array}$} \\
\hline & & Range & $\begin{array}{c}\text { Mean } \pm \\
\text { S.D }\end{array}$ & Range & Mean $\pm S . D$ & Range & Mean \pm S.D & Range & Mean $\pm S . D$ & $\mathrm{Bv} / \mathrm{sA}$ & $\mathrm{Cv} / \mathrm{sA}$ & $\mathrm{Dv} / \mathrm{sA}$ & $\mathrm{Cv} / \mathrm{sB}$ & $\mathrm{Dv} / \mathrm{sC}$ & $\mathrm{Dv} / \mathrm{s} B$ \\
\hline 1 & PI & $0.31-1.85$ & $1.01 \pm 0.36$ & $0.95-1.66$ & $1.43 \pm 0.32$ & $0.43-2.20$ & $1.39 \pm 0.44$ & $0.75-2.40$ & $1.50 \pm 0.54$ & $0.04^{*}$ & $0.003^{* *}$ & $0.003 * *$ & 0,99 & 0,83 & 0,96 \\
\hline 2 & Gl & $0.00-1.39$ & $0.27 \pm 0.30$ & $0.38-1.07$ & $0.76 \pm 0.30$ & $0.46-1.87$ & $1.09 \pm 0.44$ & $0.88-2.00$ & $1.59 \pm 0.44$ & $0.004^{* *}$ & $0.00^{* * *}$ & $0.00 * * *$ & 0,36 & $0.02 *$ & $0.008 * *$ \\
\hline 3 & PD (mm) & $1.40-1.90$ & $1.57 \pm 0.16$ & $5.00-5.17$ & $5.11 \pm 0.08$ & $4.68-6.37$ & $5.47 \pm 0.48$ & $3.30-8.23$ & $5.83 \pm 1.61$ & $0.00^{* * *}$ & $0.00 * * *$ & $0.00^{* * *}$ & 0,78 & 0,64 & 0,44 \\
\hline 4 & CAL (mm) & 0.0 & 0.0 & $2.41-2.84$ & $2.61 \pm 0.23$ & $3.19-4.86$ & $3.93 \pm 0.50$ & $5.30-7.78$ & $6.51 \pm 0.89$ & $0.00 * * *$ & $0.00 * * *$ & $0.00 * * *$ & $0.002^{* *}$ & $0.00 * * *$ & $0.00^{* * *}$ \\
\hline 5 & $\operatorname{RBC}\left(\times 10^{6} / \mu \mathrm{L}\right)$ & $3.2-6.7$ & $4.8 \pm 0.7$ & $4.51-4.73$ & $4.6 \pm 0.1$ & $3.57-5.39$ & $4.8 \pm 0.5$ & $4.07-4.96$ & $4.6 \pm 0.4$ & 0.61 & 0.95 & 0.43 & 0.77 & 0.58 & 0.77 \\
\hline 6 & $H b(g / d L)$ & $11.2-16.9$ & $13.6 \pm 1.7$ & $10.9-14.2$ & $12.6 \pm 1.4$ & $9.0-16.1$ & $13.4 \pm 1.9$ & $11.0-15.8$ & $13.3 \pm 1.4$ & 0.27 & 0.74 & 0.72 & 0.66 & 0.99 & 0.73 \\
\hline 7 & Hct $\left(\times 10^{2} \mathrm{~L} / \mathrm{L}\right)$ & $34.1-48.2$ & $41.4 \pm 3.9$ & $35.0-43.0$ & $39.4 \pm 3.3$ & $32.6-48.9$ & $41.0 \pm 4.6$ & $35.1-47.8$ & $40.6 \pm 3.6$ & 0.34 & 0.76 & 0.6 & 0.78 & 0.97 & 0.88 \\
\hline 8 & MCV (fLl) & $62.3-99.4$ & $86.9 \pm 7.9$ & $77.6-90.9$ & $85.3 \pm 5.9$ & $70.1-99.4$ & $86.6 \pm 7.8$ & $83.8-100.5$ & $89.1 \pm 5.8$ & 0.21 & 0.93 & 0.44 & 0.94 & 0.68 & 0.65 \\
\hline 9 & MCH (pg) & $18.6-34.0$ & $28.5 \pm 3.5$ & $24.2-30.0$ & $26.5 \pm 2.6$ & $19.9-34.2$ & $28.3 \pm 3.9$ & $24.9-32.7$ & $28.3 \pm 2.7$ & 0.24 & 0.84 & 0.52 & 0.62 & 0.77 & 0.39 \\
\hline 10 & MCHC (g/dL) & $28.6-35.1$ & $32.8 \pm 1.4$ & $30.7-33.0$ & $31.7 . \pm 1.0$ & $27.6-34.8$ & $32.5 \pm 2.0$ & $29.6-35.1$ & $32.8 \pm 1.7$ & 0.15 & 0.66 & 0.94 & 0.68 & 0.93 & 0.57 \\
\hline 11 & $\operatorname{ESR}(\mathrm{mm} / \mathrm{h})$ & $8.0-26.0$ & $17.8 \pm 4.5$ & $20.0-26.0$ & $23.0 \pm 2.6$ & $12.0-32.0$ & $18.4 \pm 4.6$ & $14.0-26.0$ & $19.0 \pm 4.6$ & $0.03^{*}$ & 0.69 & 0.49 & 0.16 & 0.94 & 0.3 \\
\hline 12 & $\begin{array}{l}\text { Serum Iron } \\
\text { ( } \mathrm{gg} / \mathrm{dL})\end{array}$ & 15-194 & $90.5 \pm 49.8$ & $37-134$ & $101.3 \pm 43.9$ & $25-126$ & $71.9 \pm 32.8$ & $47-135$ & $84.1 \pm 25.4$ & 0.68 & 0.18 & 0,72 & 0.25 & 0.64 & 0.66 \\
\hline 13 & $\begin{array}{l}\text { Serum Ferritin } \\
\text { (ng/mL) }\end{array}$ & $4.7-146.4$ & $45.8 \pm 34.3$ & $13.7-53.1$ & $26.3 \pm 18.1$ & $4.8-94.4$ & $40.6 \pm 30.0$ & $16.1-69.8$ & $34.9 \pm 16.7$ & 0.28 & 0.6 & 0.37 & 0.58 & 0.85 & 0.84 \\
\hline
\end{tabular}

Intergroup comparisons (with controls): Student t-test

Intragroup comparisons (B v/s C v/s D): One way ANOVA test followed by post-hoc Tukey's test

$\mathrm{n}=$ number of subjects; S.D - Standard deviation

${ }^{*} P \leqslant .05$ - Significant; ${ }^{* *} P<.01$ - Highly significant; ${ }^{* * *} P<.001$ - Very highly significant

Table 3. Results (Mean \pm standard deviation) and reference ranges for red blood cell analyses for control and study group male subjects

\begin{tabular}{|c|c|c|c|c|c|}
\hline S. No. & Variables & Reference Range & Control group & $\begin{array}{c}\text { Study group } \\
\text { (Mild + Moderate + } \\
\text { Severe periodontitis) }\end{array}$ & $p$ value* \\
\hline 1 & RBC & $4.5-5.9 \times 10^{6} / \mu \mathrm{L}$ & $5.07 \pm 0.77$ & $4.83 \pm 0.39$ & $0.21, \mathrm{NS}$ \\
\hline 2 & $\mathrm{Hb}$ & $14-17.4 \mathrm{~g} / \mathrm{dL}$ & $14.3 \pm 1.8$ & $13.67 \pm 1.54$ & 0.25, NS \\
\hline 3 & Hct & $41.5-50.4 \times 10^{2} \mathrm{~L} / \mathrm{L}$ & $43.5 \pm 3.5$ & $41.9 \pm 3.7$ & $0.18, N S$ \\
\hline 4 & MCV & $80-96 \mathrm{fL}$ & $85.7 \pm 9.6$ & $86.9 \pm 6.6$ & 0.65, NS \\
\hline 5 & $\mathrm{MCH}$ & $27.5-33.2 p g$ & $28.3 \pm 4.1$ & $28.2 \pm 3.1$ & 0.93, NS \\
\hline 6 & $\mathrm{MCHC}$ & $33.4-35.5 \mathrm{~g} / \mathrm{dL}$ & $32.8 \pm 1.8$ & $32.5 \pm 1.4$ & $0.56, \mathrm{NS}$ \\
\hline 7 & ESR & $0-15 \mathrm{~mm} / \mathrm{h}$ & $17.1 \pm 4.9$ & $18.23 \pm 3.74$ & 0.42, NS \\
\hline 8 & Serum Iron & $60-150 \mu \mathrm{g} / \mathrm{dL}$ & $106.9 \pm 49.5$ & $83.7 \pm 34.9$ & 0.09, NS \\
\hline 9 & Serum Ferritin & $15-200 \mathrm{ng} / \mathrm{mL}$ & $50.9 \pm 34.7$ & $39.8 \pm 26.6$ & $0.27, \mathrm{NS}$ \\
\hline
\end{tabular}

$\mathrm{n}=$ number of subjects; $\mathrm{NS}=$ non-significant

* Student t-test

$P \leqslant .05$ - significant 
to the control group showed a slightly higher proportion of patients with lower RBC counts $136.67 \%$ and $26 \%$ respectively; $P=.40)$, lower $\mathrm{Hb}$ levels $(40 \%$ and $36 \%$ respectively; $P=.79$ ) and lower serum iron levels $(36.67 \%$ and $30 \%$ respectively; $P=.58)$.

\section{DISCUSSION}

In the present cross-sectional study, the clinical periodontal parameters, RBC parameters and serum iron and ferritin levels were compared between the control (subjects without periodontitis) and study groups (chronic generalized periodontitis) and within the various study groups that differ in their disease severity (mild, moderate and severe periodontitis).

Results showed that the study groups had significantly higher clinical parameters (PI, GI, PD and CAL) than the control group, because of the presence of periodontitis in the study group patients. The PI and PD values were not significantly different among the mild, moderate, and severe periodontitis groups; however, the level of significance of CAL increased as the disease severity increased. Thus, CAL proved to be a better indicator of periodontal disease progression than PD because of its measurement from a fixed reference point i.e. CEJ unlike the unstable soft tissue landmark (GM) used for PD measurement. The GI was significantly more in the severe periodontitis group than in the other study groups; however, no significant difference was seen between the mild and moderate periodontitis groups.

The results for the comparison of hematological and biochemical parameters between the control and study groups revealed 3 important observations: (1) The hematological and biochemical parameters were not significantly different between the control and study groups or among the study groups, except for ESR, which was significantly higher in the mild periodontitis group than the control group; (2) male and female patients of both study and control groups exhibited similar

Table 4. Results (Mean \pm standard deviation) and reference ranges for red blood cell analyses for control and study group female subjects.

\begin{tabular}{|c|c|c|c|c|c|}
\hline S. No. & Variables & Reference Range & Control group & Study group (Mild + Moderate + Severe periodontitis) & p value* \\
\hline 1 & RBC & $4.5-5.1 \times 10^{6} / \mu \mathrm{L}$ & $4.38 \pm 0.46$ & $4.26 \pm 0.36$ & 0.53, NS \\
\hline 2 & $\mathrm{Hb}$ & $12.3-15.3 \mathrm{~g} / \mathrm{dL}$ & $12.6 \pm 0.92$ & $12.11 \pm 1.52$ & 0.36, NS \\
\hline 3 & Hct & $36-45 \times 10^{2} \mathrm{~L} / \mathrm{L}$ & $38.7 \pm 2.6$ & $37.3 \pm 2.9$ & $0.26, \mathrm{NS}$ \\
\hline 4 & MCV & $80-96 \mathrm{fL}$ & $88.4 \pm 4.8$ & $88.0 \pm 8.1$ & 0.89, NS \\
\hline 5 & $\mathrm{MCH}$ & $27.5-33.2 \mathrm{pg}$ & $28.8 \pm 1.6$ & $28.7 \pm 4.3$ & $0.94, \mathrm{NS}$ \\
\hline 6 & $\mathrm{MCHC}$ & $33.4-35.5 \mathrm{~g} / \mathrm{dL}$ & $32.7 \pm 0.7$ & $32.4 \pm 2.7$ & $0.70, \mathrm{NS}$ \\
\hline 7 & ESR & $0-20 \mathrm{~mm} / \mathrm{h}$ & $18.8 \pm 3.9$ & $21.75 \pm 5.70$ & 0.17 , NS \\
\hline 8 & Serum Iron & $60-150 \mu \mathrm{g} / \mathrm{dL}$ & $69.0 \pm 42.9$ & $67.9 \pm 34.3$ & $0.95, \mathrm{NS}$ \\
\hline 9 & Serum Ferritin & $12-150 \mathrm{ng} / \mathrm{mL}$ & $39.1 \pm 34.0$ & $29.3 \pm 19.9$ & 0.46, NS \\
\hline
\end{tabular}

Table 5. Number (\%) of control subjects and periodontitis patients with values for red blood cell parameters outside reference ranges (below or above ref.), with $p$-values.

\begin{tabular}{|c|c|c|c|c|}
\hline S. No. & Variables & $\begin{array}{l}\text { Control group } \\
\qquad(n=50)\end{array}$ & $\begin{array}{l}\text { Study group (Mild + Moderate }+ \text { Severe periodontitis }) \\
\qquad(\mathrm{n}=90)\end{array}$ & $\mathrm{p}$ value* \\
\hline 1 & RBC below ref. & $13(26 \%)$ & $33(36.67 \%)$ & $0.40, \mathrm{NS}$ \\
\hline 2 & $\mathrm{Hb}$ below ref. & $18(36 \%)$ & $36(40 \%)$ & $0.79, \mathrm{NS}$ \\
\hline 3 & Hct below ref. & $17(34 \%)$ & $18(20 \%)$ & $0.24, \mathrm{NS}$ \\
\hline 4 & MCV below ref. & $7(14 \%)$ & $9(10 \%)$ & $0.69, \mathrm{NS}$ \\
\hline 5 & $\mathrm{MCH}$ below ref. & $20(40 \%)$ & $18(20 \%)$ & 0.08, NS \\
\hline 6 & $\mathrm{MCHC}$ below ref. & $32(64 \%)$ & $54(60 \%)$ & 0.79, NS \\
\hline 7 & ESR above ref. & $33(66 \%)$ & $42(46.67 \%)$ & 0.11 , NS \\
\hline 8 & Serum Iron below ref. & $15(30 \%)$ & $33(36.67 \%)$ & 0.58, NS \\
\hline 9 & Serum Ferritin below ref. & $10(20 \%)$ & $9(10 \%)$ & 0.27, NS \\
\hline
\end{tabular}

$\mathrm{n}=$ number of subjects; NS $=$ non-significant

*z-test for proportion

$P \leqslant .05$ - significant 
hematological and biochemical parameters, thus, indicating that gender does not have any influence on these parameters; and (3) no significant difference could be demonstrated between the number of patients showing the outside reference range values in the control and study groups.

These observations from our study were in complete contrast to those of previous studies $^{8-10,12,13}$ that observed anemic states in periodontitis patients. In 1945, it was reported that periodontal therapy resulted in the resolution of anemia. ${ }^{8}$ In addition, it was found that $58 \%$ of the female patients with periodontitis and $30 \%$ of the male patients with periodontitis had depressed Hct levels. ${ }^{9}$ Hutter et al ${ }^{12}$ showed that periodontitis patients (110 men and women) have lower Hct levels, lower RBC counts and lower Hb levels, thus, terming this condition as ACD occurring because of depressed erythropoiesis. Further, a more recent study by Gokhale et $\mathrm{a}^{13}$ also reported results similar to those of Hutter et al ${ }^{12}$ in 30 male chronic periodontitis patients in an Indian population. Nevertheless, Wakai et al ${ }^{11}$ did not observe a relationship between increasing CPITN scores and $\mathrm{Hb}$ levels, which was in accordance with our study results.

ESR is a measure of the rate at which erythrocytes sediment in anticoagulated whole blood under a given set of conditions. ${ }^{7}$ Accelerated erythrocyte aggregation is caused by large, asymmetrical plasma proteins (fibrinogen, immunoglobulins, lipoproteins and a-2 macroglobulin) and inflammation related proteins (cytokines and chemokines) inhibiting the negative electrical forces that normally keep the erythrocytes apart. One of the major factors (positive correlation) influencing ESR is the Hct parameter. ${ }^{7,12}$ In the present study, both Hct and ESR were not significantly different among the study groups, but unlike Hct which showed no significant difference between the control and study groups, ESR was significantly higher only in the mild periodontitis group. In addition, ESR was found to be raised in $66 \%$ of the periodontitis patients and $46.67 \%$ of the controls, with the difference between them being non-significant. These results were in contrast with that of an earlier study by Hutter et $\mathrm{al}^{12}$ who found lower Hct and higher ESR values in patients with moderate and severe periodontitis than in the control subjects, but lesser proportions of patients affected with high ESR $(24 \%$ of the periodontitis patients and $10 \%$ of the control subjects). For this observation of lesser proportion of periodontitis patients and control group patients showing higher ESR values, Hutter et $\mathrm{al}^{12}$ reasoned that the elevation of ESR caused by the inflammatory process may be masked through a depressed Hct value also as a result of the same inflammatory process. In our study, mean ESR values (in $\mathrm{mm} / \mathrm{h}$ ) were not significantly different between the mild $(23.0 \pm 2.6)$, moderate $(18.4 \pm 4.6)$, and severe $(19.0 \pm 4.6)$ chronic periodontitis patients, as opposed to the results of an earlier study18 in which mean ESR values were highest in patients with severe chronic periodontitis and lowest in patients with mild chronic periodontitis. Thus, the diagnostic value of this parameter of inflammation for measuring systemic involvement in periodontitis seems to be limited. ${ }^{12}$

In our study, when biochemical parameters were analyzed, below normal serum iron and ferritin levels were found in both the periodontitis patients $(30 \%$ and $20 \%$ respectively) and the control group subjects $(36.67 \%$ and $10 \%$ respectively); the difference between the 2 groups was non-significant. The mean values of serum iron $(\mu \mathrm{g} / \mathrm{dL})$ and serum ferritin $(\mathrm{ng} / \mathrm{mL})$ in the control $(90.5$ and 45.8, respectively), mild periodontitis (101.3 and 26.3, respectively), moderate periodontitis $(71.9$ and 40.6, respectivelyl and severe periodontitis (84.1 and 34.9, respectively) groups were all in the normal range. These results were contradictory to those obtained by Miglani et al ${ }^{19}$ who claimed a definite negative correlation between serum iron values and periodontal disease status as the advancement of periodontal disease was associated with hypoferremia. Similarly, a study done to evaluate the blood changes in periodontal disease by Chawla et a ${ }^{20}$ found hypoferremia in periodontitis patients wherein 16 male patients $(72.7 \%)$ and 6 female patients $(75 \%)$ with moderate to severe periodontitis had low normal or below normal serum iron values. However, there is a lack of literature to correlate serum ferritin values and periodontal disease.

Thus, the results of the present study show no significant difference between the chronic periodontitis patients and control group subjects in terms of hematological and biochemical parameters, which was contradictory to the results of earlier studies ${ }^{12,13}$ that claimed an ACD- like condition 
associated with periodontal disease. ACD, which is defined as a mild anemia associated with chronic inflammatory, infectious, traumatic, or neoplastic illness, shows a characteristic disturbance of iron metabolism. ${ }^{7}$ The hallmark sign is normal or increased iron stores (serum ferritin) in the presence of hypoferremia. ${ }^{7}$ In the present study, since the mean values of both serum iron and serum ferritin in the control and study groups were in the normal range, the presence of both $A C D$ and iron deficiency anemia (characterized by the reduction of both serum iron and serum ferritin) can be ruled out in these subjects.

The ACD detected in periodontitis patients in a previous study by Hutter et $\mathrm{al}^{12}$ was in fact termed as a "slight" form of anemia by Loos, ${ }^{21}$ because chronic periodontitis is a mild inflammatory condition.13 Thus, there is always a possibility of the presence or absence of this condition depending on the amount of inflammation present and host response to the inflammation. This is evident from the present study where although inflammation of the periodontium was significantly more in the periodontitis groups than the control group, there was no significant difference between the 2 groups in terms of hematological and biochemical parameters.

Therefore, from the results of this study, it can be hypothesized that neither the presence nor the severity of periodontitis had any effect on the hematological and biochemical parameters of the study subjects. An obvious shortcoming of the present study is its short term observational nature. Therefore, further research in the form of longitudinal studies with a larger sample size and comparison of hematological and biochemical parameters before and after periodontal therapy is required.

\section{CONCLUSION}

The present cross-sectional study was designed to assess whether periodontitis may cause an anemic state by comparing the RBC parameters and the serum iron and ferritin levels between the control (subjects without periodontitis) and study groups (chronic generalized periodontitis) and also within the various study groups that differ in their disease severity (mild, moderate and severe periodontitis). The results of the study showed the following:
- The hematological and biochemical parameters were not affected by the severity of chronic periodontitis

- The presence of periodontitis in the subjects did not influence the hematological and biochemical parameters, except for ESR which was significantly higher in the mild periodontitis group than the control group

- The hematological and biochemical parameters were not significantly different among the male and female subjects of both control and study groups.

Thus, the notion of periodontal disease leading to ACD may be viewed with caution and needs further investigation.

\section{AKNOWLEDGEMENTS}

The authors express their sincere thanks to the staff of Central Laboratory, Bapuji Hospital, Davangere, Karnataka, India for laboratory procedures, and to Mr. Sangam, Biostatistician, J.J.M Medical College, Davangere, Karnataka, India for statistical analyses of the study data. We are also thankful to Editage company la division of Cactus Communications Pvt. Ltd., Memphis, USA) for editing the paper for language. The authors have received no financial support from any sources and report no conflicts of interest related to this study.

\section{REFERENCES}

1. Enhos S, Duran I, Erdem S, Buyukbas S. Relationship between iron-deficiency anemia and periodontal status in female patients. J Periodontol 2009;80:1750-1755.

2. Mustapha IZ, Debrey S, Oladubu M, Ugarte R. Markers of systemic bacterial exposure in periodontal disease and cardiovascular disease risk: A systematic review and metaanalysis. J Periodontol 2007;78:2289-2302.

3. Sim SJ, Kim HD, Moon JY Zavras Al, Zdanowicz J, Jang SJ, Jin BH, Bae KH, Paik DI, Douglass CW. Periodontitis and the risk for non-fatal stroke in Korean adults. $J$ Periodontol 2008;79:1652-1658.

4. Wimmer G, Pihlstrom BL. A critical assessment of adverse pregnancy outcome and periodontal disease. J Clin Periodontol 2008;35(Suppl. 8):380-397.

5. Mealey BL, Rose LF. Diabetes mellitus and inflammatory periodontal diseases. Compend Contin Educ Dent 2008;29:402-408, 410, 412-413.

6. De Benoist B, McLean E, Egli I, Cogswell M. Worldwide prevalence of anemia 1993-2005: WHO global database on anemia. Geneva: World Health Organization Press, 2008. p. 7. 
7. Johnson MA. Iron: nutrition monitoring and nutrition status assessment. J Nutr 1990;120:1486-1491.

8. Siegel EH. Total erythrocyte, leukocyte and differential white cell counts of blood in chronic periodontal disease. $J$ Dent Res 1945;24:270-271.

9. Lainson PA, Brady PP, Fraleigh CM. Anemia, a systemic cause of periodontal disease? J Periodontol 1968;39:35-38.

10. Chawla TN, Kapoor KK, Teotia SP, Singh NK. Anemia and periodontal disease - a correlative study. J Indian Dent Assoc 1971;43:67-78.

11. Wakai K, Kawamura T, Umemura O, Hara Y, Machida J, Anno T, Ichihara Y, Mizuno Y, Tamakoshi A, Lin Y, Nakayama T, Ohno Y. Associations of medical status and physical fitness with periodontal disease. J Clin Periodontol 1999;26:664-672.

12. Hutter JW, Van der Velden U, Varoufaki A, Huffels RA, Hoek FJ, Loos BG. Lower numbers of erythrocytes and lower levels of hemoglobin in periodontitis patients compared to control subjects. J Clin Periodontol 2001;28:930-936.

13. Gokhale SR, Sumanth S, Padhye AM. Evaluation of blood parameters in patients with chronic periodontitis for signs of anemia. J Periodontol 2010;81:1202-1206.

14. Lee GR. The anemia of chronic disease. Semin Hematol 1983;20:61-80.

15. Consensus Report. Chronic periodontitis. Ann Periodontol 1999;4:38-39.

16. Silness J, Loe H. Periodontal disease in pregnancy. II. Correlation between oral hygiene and periodontal condition. Acta Odontol Scand 1964;22:121-135.

17. Loe H, Silness J. Periodontal disease in pregnancy. I. Prevalence and severity. Acta Odontol Scand 1963;21:533-551.

18. AlGhamdi AS. Effect of chronic periodontal diseases on erythrocyte sedimentation rate. Egypt Dent J 2009;55:26412648.

19. Miglani DC, Rajasekher A, Shyamala S, Prasad PS. Blood studies in periodontal disease. II. Serum iron and copper values. J Indian Dent Assoc 1969;4:189-193.

20. Chawla TN, Kumar S, Mathur MN. Blood changes in periodontal disease. J All India Dent Assoc 1965;37:224-227.

21. Loos BG. Systemic markers of inflammation in periodontitis. J Periodontol 2005;76:2106-2115. 